\title{
New guidelines on asthma management
}

\author{
Aim to control symptoms rapidly, with higher initial doses of steroid and earlier use \\ of $\beta$ agonists
}

$\mathrm{T}$ The British guidelines on the management of asthma first appeared in 1990 in the $B M J .{ }^{12}$ Two years later revised guidelines, extended to cover asthma in childhood, were distributed to all hospitals and general practitioners in Britain. ${ }^{3}$ They have come to be widely respected as a clear and practical statement of best practice in the management of asthma. This month sees the publication of a review and a position statement commenting on the guidelines in the light of recent evidence.

The participants for the latest review were those from the 1993 paper, if they wished to continue, or replacements as needed. Background papers were produced and subsequently published. ${ }^{5}$ The summary statement was discussed and agreed in 1995, and it is disappointing that publication has been delayed until 1997. The summary statement should be read in conjunction with the 1993 guidelines.

Most of the 1993 advice remains valid, but there are important changes. The new guidelines reiterate the importance of a correct diagnosis and the dangers of escalation of treatment in other unresponsive conditions. They emphasise the need to gain initial control of asthma. This may mean starting with a higher dose of inhaled or oral corticosteroids and then stepping down the treatment, rather than gradually increasing the intensity of treatment until control is achieved. The aims are to control symptoms rapidly and win patients' confidence. Stepping down to avoid prolonged unnecessary treatment is important, but the optimal timing of such reductions remains uncertain.

The advice on long acting inhaled $\beta$ agonists has also changed. The 1993 guidelines advocated these as an addition to high dose inhaled corticosteroids or as an alternative in a few patients with particular problems. In the latest guidelines the threshold for using long acting $\beta$ agonists is lower. When lower dose inhaled corticosteroids do not give adequate control the alternatives of salmeterol and higher dose inhaled corticosteroids are given equal weighting.

In the section on childhood asthma, children under 5 years old are dealt with as a distinct group while older children and adults have similar treatment programmes. For children under 5, sodium cromoglycate and inhaled corticosteroids are now offered as alternatives for first line regular inhaled prophylactic treatment, rather than recommending sodium cromoglycate before inhaled corticosteroids.
The new guidelines contain useful practical information on inhaler devices, with a recognition that the range of devices now available may render nebulisers unnecessary in many clinical situations. Advice is given on the forthcoming change to non-chlorofluorocarbon propellants for metered dose inhalers, which will feel and taste different but have been shown to be safe and effective. As the range of inhaler devices increases, the information on their lung deposition and delivery does not seem to expand in parallel. Devices cannot be changed on the assumption that the same dose will be delivered to the patient's airways, and prescribers must be aware of the delivery characteristics of any device they prescribe.

The position on managing asthma in partnership with patients has changed, with definite evidence of benefit from patient education and the use of self management plans. Examples of a practical approach might have been helpful here. In one recent survey of general practitioners this was the commonest request for addition to the next guidelines. ${ }^{6}$

Increasingly it is accepted that guidelines should have a clear evidence base. The British guidelines represent an expert consensus with no formal account of how the literature was searched and assessed. Some statements in the guidelines suggest the existence of evidence without citing the appropriate references; examples include the link between passive smoking and childhood asthma and the use of once daily inhaled budesonide. This contrasts with the well defined methodology of the North of England group, which published its evidence based guidelines for the primary care management of asthma in this journal in $1996 .^{78}$

In some areas there is a lack of reliable published evidence. The North of England guidelines state that "as there is no good evidence of clinically important differences between differing inhaled steroids, patients should be treated with the cheapest inhaled steroid that they can use and which controls their symptoms." It seems entirely reasonable for guidelines to include considerations of cost. Prescriptions for inhaled corticosteroids cost over $£ 200 \mathrm{~m}$ in England alone in 1995 (Department of Health Statistics Division 1E, private communication), and different preparations vary widely in price.

When there is a lack of evidence rather than evidence of lack of benefit it can be helpful to have the opinion of experts, providing it is made clear that this 
is opinion and not evidence. In places the British guidelines do this clearly, as in their advice on doubling inhaled corticosteroid dose if there is deterioration of control or upper respiratory tract infection. The opinion and experience of experts will remain important in the development of guidelines, but the experts should take care to convince us that the evidence for their opinions has been systematically appraised. This should be clearer in the next full rewrite of the guidelines. The British asthma guidelines have been widely disseminated, probably more so than any other similar guidelines. They are highly regarded, and used widely for clinical audit. This latest review will help to maintain their important role in the promotion of better asthma care.

Duncan Keeley General practitioner

The Health Centre,

East Street,

Thame,

Oxon OX9 3JZ

John Rees

Consultant physician and senior lecturer

UMDS,

Guy's Hospital,

London SE1 9RT
1 Statement by the British Thoracic Society, Research Unit of the Royal College of Physicians of London, King's Fund Centre, National Asthma Campaign. Guidelines for the management of asthma in adults: I chronic persistent asthma. BMJ 1990;301:651-3.

2 Statement by the British Thoracic Society, Research Unit of the Royal College of Physicians of London, King's Fund Centre, National Asthma Campaign. Guidelines for the management of asthma in adults: II Campaign. Guidelines for the management

3 British Thoracic Society, British Paediatric Association, Royal College of Physicians, King's Fund Centre, National Asthma Campaign, Royal College of General Practitioners, General Practitioners in Asthma Group, British Association of Accident and Emergency Medicine, British Paediatric Respiratory Group. Guidelines on the management of asthma. Thorax 1993;48:S1-24.
4 British asthma guidelines coordinating committee. British guidelines on asthma management: 1995 review and position statment. Thorax 1997;52:S1-24.

5 Harrison BDW. Guidelines in asthma. Respir Med 1996;90:375-8.

6 McGovern V, Crockett A. 1993 BTS guidelines: impact and shortfall. Asthma J 1996;1:30-1.

7 Eccles M, Clapp Z, Grimshaw J, Adams P, Higgins B, Purves I, et al. North of England guidelines development project: methods of guideline development. BMJ 1996;312:760-2.

8 North of England Guidelines Development Group. North of England evidence based guidelines development project: summary version of evidence based guidelines for the primary care management of asthma in adults. $B M J$ 1996;312:762-6.

\section{Managing measles}

\section{Integrated case management reduces disease severity}

$\mathrm{M}$ easles remains a leading cause of childhood morbidity and mortality in developing countries, with fatality rates in hospitalised children often exceeding $10 \% .^{1}$ Most deaths follow complications such as pneumonia, croup, and diarrhoea and are often associated with malnutrition. Reducing the severity of disease through appropriate management should thus be a priority. What is surprising and rather disturbing, however, is the lack of published scientific information on issues that are central to developing a sound basis for managing measles. A recent review of clinical problems associated with measles has highlighted the paucity of data on risk factors, aetiology, natural course, and management (except vitamin A) of the common complications of measles. ${ }^{2}$ The problems with prophylactic antibiotic trials are discussed by Shann in this week's $B M J$. $^{3}$

Nevertheless, on the basis of the available data, the World Health Organisation's Expanded Programme on Immunisation has developed a policy document on integrated management of measles to help health workers in developing countries to reduce the severity of measles. ${ }^{4}$ The basic principles are outlined in the box.

Severe disease should be anticipated if the child is from a high risk area (for example, areas with vitamin A deficiency, poor socioeconomic status, or low immunisation coverage) or from a high risk group (for example, young infants, immunocompromised children (including those with HIV or AIDS), migrants, refugees, or those with severe malnutrition). ${ }^{4}$ Even though hospital resources are limited in many developing countries, children with severe pneumonia, dehydration, croup, malnutrition, or neurological complications must be admitted to hospital for treatment. Vitamin A deficiency is a recognised risk factor for severe measles. ${ }^{5}$ In hospital based studies, treatment with high dose vitamin A significantly reduced morbidity and mortality. ${ }^{6}$ Large community based intervention trials evaluating the effect of vitamin A prophylaxis on overall childhood mortality have also shown a reduction in mortality from measles. $^{7}$

Measles is an extremely catabolic event associated with reduced intake of food, increased gastrointestinal losses, and rapid weight loss. ${ }^{8}$ Breast feeding should be encouraged to provide nutritional support and should

\section{Basic principles of management}

- Anticipate complications in high risk groups

- Admit severely ill children to hospital

- Give paracetamol if temperature exceeds $39^{\circ} \mathrm{C}$

- Treat with high dose vitamin A

- Encourage breast feeding

- Provide nutritional support to all children

- Treat eyes promptly to prevent blindness

- Use antibiotics only for clear indications

- Give oral rehydration solution for diarrhoea

- Treat multiple complications at the same time

- Monitor growth regularly 
be continued even if the infant has diarrhoea. If the child refuses feeds a nasogastric tube should be passed and additional fluids given to prevent or treat dehydration. If dysentery is present an appropriate antibiotic should be given for shigella infection.

Severe mouth ulceration, usually a consequence of secondary herpes infection, contributes to reduced fluid and food intake. Regular mouth washes with clean water should be used, and 1\% gentian violet should be applied to mouth lesions. Secondary eye infections should be prevented by regular cleansing of eyes with water and the application of tetracycline eye ointment. If there is any evidence of xerophthalmia, clinicians should ensure that the child has received the two doses of vitamin A as part of the treatent for measles. A third dose of vitamin A is recommended four to six weeks later. A protective eye pad will help to prevent secondary infection. Severe pneumonia and otitis media should be treated with an appropriate antibiotic and a bronchodilator if there is wheezing. Inhaled oxygen is mandatory if there is clinical evidence of severe pneumonia. Children with severe stridor must be referred to a hospital with facilities for airway intervention. Nebulised adrenaline may also be useful.

One of the controversies regarding management of measles is the use of prophylactic antibiotics. ${ }^{23}$ The argument for such a strategy is the high risk of secondary bacterial infections and consequent mortality. On the other hand, routine use of antibiotics is costly and may result in unnecessary complications such as antibiotic associated diarrhoea, severe drug reactions, and the emergence of drug resistant organisms. In this week's $B M J$, a meta-analysis of five randomised controlled clinical trials done between 1939 and 1954 indicate that prophylactic antibiotics were not beneficial in reducing mortality (p 334). ${ }^{3}$ Even though no well conducted placebo controlled clinical trials have been done in developing countries, two studies suggested that prophylactic antibiotics may be useful. An outpatient study from India in 1967 found that, of 80 children with measles who were given placebo, 11 developed important radiological features of pneumonia, compared with none of the 78 children treated prophylactically with tetracycline. ${ }^{9}$ A descriptive study from Senegal reported that routine treatment with co- trimoxazole in children younger than 3 years may have been associated with a reduction of respiratory complications and mortality. ${ }^{10}$

Even though controlled clinical trials to evaluate the efficacy of prophylactic antibiotics may be difficult to do, ${ }^{2}$ a recent WHO report on clinical research on measles treatments has identified this as a research priority. ${ }^{11}$ Until the issue is resolved it must be emphasised that antibiotics should be given only if there is a specific indication such as pneumonia, otitis media, or dysentery. Prophylactic antibiotics may be justifiable in children who are at an additional risk of secondary bacterial infections, such as those with severe malnutrition, AIDS, or xerophthalmia. Finally, it should be remembered that measles is preventable by immunisation and that, ultimately, the control of measles depends on obtaining and maintaining a measles vaccine coverage that is in excess of $90 \%$.

Greg Hussey Associate professor

Department of Paediatrics and Child Health,

University of Cape Town,

Rondebosch,

Cape Town,

South Africa

1 Morley D. Severe measles in the tropics: I. BMJ 1969;i:297-300.

2 Hussey GD, Clements CJ. Clinical problems in measles case management. Ann Trop Ped (in press).

3 Shann F. Prophylactic antibiotics for children with measles: a meta-analysis. BMJ 1997;314:334-6.

4 World Health Organisation. Case management of measles-a policy document. Geneva: WHO, 1996.

5 Butler JC, Havens PL, Sowell AL, Huff DL, Peterson DE, Day SE, et al. Measles severity and serum retinol (vitamin A) concentration among children in the United States. Pediatrics 1993;91:1176-81.

6 Hussey GD, Klein MA. A randomised controlled trial of vitamin A in children with severe measles. $N$ Engl J Med 1990;323:160-4.

7 Beaton GH, Martorell R, L'Abbe K, Edmonston B, McCabe G, Ross AC, et al. Effectiveness of vitamin A supplementation in the control of young child morbidity and mortality in developing countries. Final report to CIDA. Toronto: University of Toronto, 1992.

8 Dossetor JFB, Whittle HC. Protein-losing enteropathy and malabsorption in acute measles enteritis. BMJ 1975;ii:592-3.

9 Prasad R, Marthur GP, Trehan OP, Mehrotra ML, Dayal RS. A clinical and radiological study of measles. Indian Pediatr 1967;4:243-50.

10 Samb B, Simondon F, Aaby P, Whittle H, Seck AWMC. Prophylactic use of antibiotics and reduced case fatality in measles infection. Pediatr Infect Dis J 1995; 14:695-6.

11 World Health Organisation. Clinical research on treatment of measles: report of a meeting. Geneva: WHO, 1995.

\title{
Reducing vitamin A deficiency
}

\author{
Could save the eyesight and lives of countless children
}

$\mathrm{T}$ The World Health Organisation considers vitamin A deficiency to be a public health problem in over 60 countries, putting at risk the lives and eyesight of an estimated 250 million preschool children. ${ }^{1}$ It is a major cause of morbidity and mortality ${ }^{2}$ and the single most important cause of blindness in children in developing countries, ${ }^{3}$ and it is entirely preventable.

Our bodies need vitamin A for the maintenance of epithelial surfaces, for immune competence, ${ }^{4}$ for the normal functioning of the retina, and for growth, development, and reproduction. We obtain vitamin A from two sources: firstly, from fat soluble vitamin A present in milk, eggs, butter, and fish liver oils; secondly as provitamin A carotenoids in dark green leafy vegetables, red palm oil, and in red or orange coloured fruits and vegetables such as mango, papaya, sweet potato, and carrots. Most of the ingested retinol is absorbed in the small intestine and transported to the liver, where it is stored as retinyl palmitate. When required it is released into the blood stream in combination with retinol binding pro- 
tein and is taken up by target cells throughout the body.

When intake of vitamin $\mathrm{A}$ is inadequate to meet the body's needs, the liver stores are depleted to maintain serum retinol at a normal concentration. If intake is low over a prolonged period the serum retinol concentration falls, which can result in clinical vitamin A deficiency, called xerophthalmia, and characterised by the ocular features of night blindness, keratomalacia (Bitot's spots, corneal drying (xerosis), and corneal ulceration, softening, and necrosis), and a generalised impaired resistance to infection. A child with inadequate liver stores of vitamin $\mathrm{A}$ is susceptible to blinding xerophthalmia and respiratory infection that can lead to death from febrile illnesses, notably measles, and gastroenteritis. At least five million children develop xerophthalmia each year, of whom up to half a million go blind. ${ }^{5}$ More than half of these blind children will die during childhood. ${ }^{2}$

How can the problem of vitamin A deficiency be tackled? Firstly, the extent of the problem must be assessed in the target population. ${ }^{5}$ Cases, either active or resolved, can be looked for in urban slums, impoverished rural communities, paediatric centres dealing with malnutrition and infectious diseases, refugee camps, and schools for the blind. Interviews with staff working in such places can provide useful information. This quick and readily accessible information can tell us whether a formal scientific assessment is justified. Definitive assessment requires a population based survey of prevalence of clinical xerophthalmia, impression cytology to identify abnormal conjunctival epithelium seen in vitamin A deficiency, measurement of serum retinol concentrations, and a dietary assessment. In children aged 1-5 years a prevalence of night blindness of over $1 \%$, of Bitot's spots of over $0.5 \%$, or of a serum retinol concentration below $0.35 \mu \mathrm{mol} / 1$ of $5 \%$ is considered to indicate an important public health problem. ${ }^{1}$

A person with xerophthalmia requires immediate treatment if corneal destruction, blindness, and even death are to be avoided. Oral administration of vitamin A $200000 \mathrm{IU}$ at presentation, the following day, and a third dose a week later is recommended. ${ }^{5}$ Children under 1 year old should receive half the standard dose, and infants under 6 months old should receive a quarter. Children with marasmus or kwashiorkor need further nutritional supplementation and monitoring with additional doses of vitamin A at monthly intervals until they are clinically improved. Concurrent illness (such as malaria, intestinal parasites, dehydration, or tuberculosis) must be treated. Pregnant women should not receive large doses of vitamin $\mathrm{A}$ as it may be teratogenic, but a daily dose of 10000 IU over two weeks is safe. In all cases a diet rich in vitamin A should be advised.

Three specific community interventions have been proposed to reduce vitamin A deficiency in affected populations. Firstly, parents should be educated to provide a diet for their children that is rich in vitamin A or provitamin A and to introduce foods like mangoes, papaya, or dark green leafy vegetables into the weaning diet, mixed with a small amount of edible oil to enhance absorption. Encouraging home gardening or local cooperatives to grow such foods may be necessary in regions where they are not locally available or are too expensive. ${ }^{6}$
Secondly, periodic supplementation with a large dose of vitamin A in capsule form for children at high risk of vitamin A deficiency has been shown to reduce mortality. ${ }^{78}$ In one such intervention study in Nepal the cost per death avoided was only $\$ 11$ (£7). ${ }^{9}$ Supplementation can be integrated into existing health programmes for vaccination, family planning, and monitoring growth, though some form of supervision is required because of the danger of toxicity in overdose. Women can be given 200000 IU shortly after delivery to enrich their breast milk, and at the same time a single dose of $50000 \mathrm{IU}$ can be given to the newborn infant.

The third intervention is fortification of a common dietary constituent with vitamin A. ${ }^{6}$ This has been partially successful in central and south America and in South East Asia, with fortification of sugar or monosodium glutamate. ${ }^{10}$ However, political, technological, and economic restraints have often prevented the sustainability of such a strategy in the long term. ${ }^{6}$

The elimination of vitamin A deficiency ultimately will depend on raising living standards. ${ }^{11}$ This in turn depends on political decisions related to Third World debt, trade, and employment and a reduction in poverty, together with improvements in housing, sanitation, water supply, women's education, and primary health care. ${ }^{12}$ Campaigns to promote vaccination (notably against measles), breast feeding, family planning (to space children), and oral rehydration therapy are also important in reducing the morbidity and mortality from vitamin A deficiency. Such programmes must be targeted to reach the children in those communities at greatest risk.

Andrew R Potter Ophthalmologist

Centre Hospitalier Departemental,

BP 2248, Abomey,

Republic of Benin,

West Africa

Free educational materials (wall posters, books, videos) in English, French, and Spanish, and vitamin A capsules may be obtained from Task Force "Sight and Life," PO Box 2116, CH 4002 Basel, Switzerland.

1 World Health Organisation. Global prevalence of vitamin A deficiency. Geneva: WHO, 1995. (MDIS working paper No 2.)

2 Glasziou PP, Mackerras DEM. Vitamin A supplementation in infectious diseases: a meta-analysis. BMJ 1993;306:366-70.

3 World Health Organisation. Prevention of childhood blindness. Geneva: WHO, 1992.

4 Bates CJ. Vitamin A. Lancet 1995;345:31-5.

5 Sommer A. Vitamin A deficiency and its consequences; a field guide to detection and control. 3rd ed. Geneva: WHO, 1995

6 Underwood BA. Vitamin A prophylaxis programmes in developing countries: past experiences and future prospects. Nutrition Reviews 1990;48(7):265-74.

7 Ghana VAST Study Team. Vitamin A supplementation in northern Ghana: effects on clinic attendance, hospital admissions and mortality. Lancet 1993;342:7-12.

8 Sommer A, Tarwotjo I, Djunaedi E, West EP, Loeden AA, Tilden R, et al. Impact of vitamin A supplementation on childhood mortality: a randomised controlled community trial. Lancet 1986;i:1169-73.

9 Daulaire NMP, Starbuck ES, Houston RM, Church MS, Stukel TA, Pandey MR. Childhood mortality after a high dose of vitamin A in a high risk population. BMJ 1992;304:207-10.

10 Arroyave G, Aguilar JR, Flores M, Guzman R. Evaluation of sugar fortification with vitamin $A$ at the national level. Washington DC: Pan American Health Organisation, 1979. (Scientific publication No 384.)

11 Herrera MG, Nestel P, Amin AK, Fawzi WW, Mohamed KA, Weld L. Vitamin A supplementation and child survival. Lancet 1992;340:267-71.

12 Northrup R, Rohde J. The state of child health: the context in which vitamin A deficiency occurs. In: Public health significance of Vitamin A deficiency and its control. Bellagio meeting 1992. New York: Helen Keller International, 1993: 13-7. 


\title{
Surgery, drugs, and the male orgasm
}

\author{
Informed consent can't be assumed unless effects on orgasm have been discussed
}

$\mathrm{A}$ lthough probably essential for the survival of the species, very little is known about the male orgasm. What is known is at best confusing and provides more questions than answers. Recent studies (all observational) have been useful in two ways. Firstly, they have helped to define the anatomical and physiological changes that occur during orgasm, using modern imaging techniques on the brain and prostate. Secondly, and perhaps more important, they have documented the effect on male orgasm of certain operations (mainly prostatic) and drugs (mainly inhibitors of serotonin reuptake).

Gil-Vernet and colleagues used transrectal (endorectal) ultrasound in four volunteers to generate the first dynamic images of the events occurring in the genitourinary tract during ejaculation. ${ }^{1}$ The first detectable changes were rhythmic contractions of the prostate gland, seminal vesicles, and muscles of the perineal floor.Just before ejaculation, both preprostatic and postprostatic sphincters contracted, followed by descent of the ejaculatory ducts and a probable increase in pressure within the prostatic urethra. Relaxation of the voluntary postprostatic sphincter, together with further prostatic contractions, resulted in ejaculation. This final event was associated with the sensation of orgasm and a release of sexual tension. Over the next minute or two the anatomy returned to normal, as did the physiological changes (increased blood pressure, respiratory rate, and anal tone) that accompany orgasm. During this refractory period no further ejaculation or orgasm was possible. ${ }^{2}$

How these events fit in with the central appreciation of orgasm is difficult. The precise neural pathways are not known, but certain disturbances of normal sexual function have made one thing clear. Penile erection, ejaculation, and orgasm are mutually independent and dissociable events. Absence of the sensation of orgasm (anorgasmia) with normal ejaculation has been reported in several neurological disorders but typically in multiple sclerosis, Parkinson's disease, and Huntington's chorea. ${ }^{3}$ In addition, denervation that may follow pelvic surgery can make men impotent, yet many of these men report normal (or near normal) orgasmic sensation with or without simultaneous ejaculation. ${ }^{4}$ Men who have had lumbar sympathectomies (deliberately or as a complication of retroperitoneal lymph node dissections as part of cancer treatments) lose their ability to ejaculate, either through emission failure or retrograde ejaculation. However, they often retain their ability to experience orgasm.

Further insight has come from monitoring the results of operations on the spinal cord. The spinothalamic tracts of the upper thoracic cord seem to be important. Men who underwent bilateral anterolateral cordotomy for the relief of pain often reported the loss of orgasmic sensation. ${ }^{5}$ However, after complete transection of the cord, which might be expected to have a similarly profound effect, a third of men reported normal orgasm. ${ }^{6}$
It is interesting to speculate how this is possible. We know that certain areas of the brain have intense electrical activity during orgasm. Indeed orgasm can be induced by direct stereotactic stimulation of the septal nucleus, the area of greatest activity during orgasm. ${ }^{7}$ When other areas were stimulated-such as the postcentral gyrus-patients reported sensations that were similar to orgasm but were not linked to any erotic feelings. Neurohumoral pathways might also be important. Normal orgasm is accompanied by a transient surge in oxytocin from the neurohypophysis. ${ }^{8}$ Giving men oxytocin has been said to enhance the sensation of orgasm, while naloxone (which prevents the surge of oxytocin) seems to do the opposite. ${ }^{9}$

These observations suggest that normal orgasm results from complex neural interactions and may require a degree of central processing-a conclusion that is supported by studies using single photon emission computed tomography to create real time images of cerebral blood flow. These showed increased activity in the right prefrontal cortex during orgasm..$^{10}$

Interesting perhaps, but how might all this help clinicians? Although greater understanding might help in the management of men who lose their ability to experience orgasm, we have at present no reliable treatments. But one good thing has emerged. As a result of patients' (and some doctors') increased willingness to speak candidly about sexual function, more men with orgasmic dysfunction are being recognised. In a large, nationally representative study of prostatectomy, about half the men who were sexually active both before and three months after their operation reported altered or absent orgasmic sensation. ${ }^{11}$ This was most common in men reporting retrograde ejaculation-a side effect of transurethral prostatectomy that can be expected to occur in three quarters of men. A proportion of these men expressed their disappointment and on occasions anger (through free text replies) at not having been warned about this side effect. ${ }^{12}$ Equally important is the increasing number of men with prostate cancer who are being considered for total (radical) prostatectomy. These men are generally younger than those undergoing prostatectomy for benign disease. Most (80\%) will lose their ability to experience orgasm. ${ }^{13}$ Similar findings might be anticipated in radical operations for bladder cancer. Whatever the mechanism resulting in the loss of orgasm after these operations it is probably reasonable to assert that informed consent cannot be assumed unless the effects of surgery on orgasm have been discussed with the patient.

Drugs have also been implicated. Selective $\alpha$ blocking drugs used to improve lower urinary tract symptoms will result in a proportion of men experiencing retrograde ejaculation. Some of these men will report a change in orgasm. Perhaps the most important group of drugs (due to the possible effect on compliance) are the selective serotonin reuptake inhibitors used in affective disorders. These will abolish 
orgasm, independently of ejaculation, in up to one fifth of men. ${ }^{14}$

William D Dunsmuir Research fellow

Department of Urology,

St George's Hospital,

London SW17 0QT

Mark Emberton

Senior registrar

Institute of Urology and Nephrology,

London W1P 7PN

1 Gil-Vernet JM Jr, Alvarez-Vijande R, Gil-Vernet A, Gil-Vernet JM. Ejaculation in men: a dynamic endorectal ultrasonographical study. Br J Urol 1994;73:442-8.

2 Carmichael MS, Warburton VL, Dixon J, Davidson JM. Relationships among cardiovascular, muscular and oxytocin responses during human sexual activity. Arch Sex Behav 1994;23:59-79.

3 Federoff J, Peyser C, Franz M, Folstein S. Sexual disorders in Huntington's disease.J Neuropsychiatry Clin Neurosci 1994;6:147-53.
4 Tomic R, Sjodin JG. Sexual function in men after radical cystectomy, with or without urethrectomy. Scand J Urol Nephrol 1992;26:127-9.

5 Brindley GS. Pathophysiology of erection and ejaculation. In: Hendry W, Whitfield $\mathrm{H}$, eds. A textbook of genitourinary surgery. London: Churchill Livingstone, 1988:1083-94.

6 Alexander CJ, Sipski ML, Findley TW. Sexual activities, desire, and satisfaction in males pre- and post-spinal cord injury. Arch Sex Behav $1993 ; 22: 217-28$.

7 Heath RG. Pleasure and brain activity in man. J Nerv Ment Dis 1972;154:363-9.

8 Carter CS. Oxytocin and sexual behaviour. Neurosci Biobehav Rev 1992;16:131-44.

9 Murphy MR, Checkley SA, Seckl JR, Lightman SL. Naloxone inhibits oxytocin release at orgasm in man. J Clin Endocrinol Metab 1990;71:1056-8

10 Tiihonen J, Kuikka J, Kupila J. Increase in cerebral blood flow of right pre-frontal cortex in man during orgasm. Neurosci Letters 1994;170:241-3.

11 Dunsmuir WD, Emberton M, Neal DE, on behalf of the steering group of the National Prostatectomy Audit. There is significant sexual dissatisfaction following TURP. Br J Urol 1996;77:161A

12 Meredith P, Emberton M, Wood C, Smith J. Comparisons of patients' needs for information on prostate surgery with printed materials provided by surgeons. Quality in Health Care 1995;4:18-23.

13 Koeman M, Van Driel MF, Weijmar Schultz WCM, Mensink HJA. Orgasm after radical prostatectomy. Br J Urol 1996;77:861-4.

14 Seagraves RT. Antidepressant induced orgasm disorder.J Sex Marital Ther 1995;21:192-201.

\section{Cardiac sarcoidosis}

\section{A potentially fatal condition that needs expert assessment}

C ardiac arrhythmias and sudden death are likely among patients known to have cardiac lesions from sarcoidosis. Other clinical presentations include conduction defects, congestive heart failure, and a picture suggesting myocardial infarction-but the first evidence of cardiac sarcoidosis may be provided by a pathologist after the sudden death of someone who had been completely free of symptoms. ${ }^{1}$

Attempts have been made to assess the prevalence of cardiac sarcoidosis. Mikhail et al studied 147 consecutive patients presenting with sarcoidosis and found 14 with electrocardiographic abnormalities; 10 of these had no symptoms related to the heart. ${ }^{2}$ Stein $e t$ $a l$ surveyed 80 selected patients aged under 40 years, of whom only five were white and 47 had chronic disease. $^{3}$ Electrocardiographic abnormalities of conduction or repolarisation were detected in 41 of these 80 patients, none of whom had cardiac symptoms.

In two other large series of unselected patients the proportion with clinical evidence of granulomatous changes in the heart was small. Scadding and Mitchell reported that, of 500 consecutive patients under their care, only four showed such evidence. ${ }^{1}$ In the series of 702 patients reported by Hagemann and Wurm 5\% had clinical evidence of cardiac sarcoidosis, although cardiac lesions were found at necropsy in 15\%.

In necropsy studies of sarcoidosis the proportion of patients with granulomas in the heart is always higher than the proportion known to have had cardiac sarcoidosis during life. Matsui et al studied 42 patients with myocardial sarcoidosis; in only five of these had sarcoidosis been diagnosed in life, and death had been sudden in $16 .{ }^{5}$ Roberts et al reviewed 113 necropsies of patients with cardiac sarcoidosis, in 89 of whom it had been the cause of death. ${ }^{6}$ The diagnosis of sarcoidosis had been made during life in only 24 , and death had been sudden in 60. Fleming collected the records of patients throughout Britain in whom the diagnosis of sarcoidosis had been reached either during life or at necropsy. ${ }^{7} \mathrm{He}$ accumulated a series of 138 fatalities among 300 patients with sarcoid heart disease. At presentation $73 \%$ had ventricular or supraventricular arrhythmia, 26\% had complete heart block, and 24\% had congestive cardiomyopathy. Sixty one per cent had right or left bundle branch block or partial heart block. Sudden death had occurred in 77 cases, and in 49 cardiac sarcoidosis had not been diagnosed previously.

Thus, the heart may have extensive sarcoid lesions without clinical symptoms or evidence of disease elsewhere. Sudden death is the most common first manifestation of cardiac sarcoidosis, though some patients have antecedent dysrhythmias. Can cardiac lesions be diagnosed earlier? We suggest that 24 hour electrocardiographic monitoring and echocardiography is performed and generalised granulomatosis confirmed by tissue biopsy of affected organs or by the Kveim-Siltzbach test.

If coronary heart disease can be excluded perfusion defects in thallium-201 myocardial scintigraphy may suggest sarcoidosis, particularly if they are absent or smaller during exercise or after dipyridamole infusion. ${ }^{89}$ Other scintigraphic investigations currently being studied include the combination of thallium-201 and gallium- 67 imaging of the heart, especially with the use of single photon emission computed tomography (SPECT) ${ }^{10}$ Fab fragments of antimyosin antibodies labelled with indium-111, ${ }^{11}$ tomoscintigraphy with technetium-99m, ${ }^{12}$ and gated cardiac magnetic resonance imaging.

Endomyocardial biopsy may yield sarcoid granulomas, but, because of the patchy distribution of the disease, a negative result does not exclude the diagnosis. ${ }^{13}$ Oakley considers that sarcoid infiltration is one of the few causes of focal left ventricular abnormality in the absence of disease of the major coronary arteries. ${ }^{14}$ The distribution is typically in the proximal portion of 
the left ventricle and upper septum, where it may produce akinesia or hypokinesia.

Myocardial sarcoidosis is difficult to diagnose and has a treacherous course that may be fatal. Corticosteroids may lead to clinical improvement but should be reserved for patients in whom the diagnosis of cardiac sarcoidosis is reasonably certain. Minor electrocardiographic changes occurring alone without any supporting evidence of myocardial damage are not an indication for treatment. The dose should be high - of the order of $60 \mathrm{mg}$ prednisolone daily or more-and treatment will need to be continued with a maintenance regimen to preserve any improvement gained.

In intractable cases and in patients who find the side effects of corticosteroids intolerable an alternative is the use of pulsed intravenous methylprednisolone with a lower maintenance dose of oral prednisolone. ${ }^{15}$ The addition of hydroxychloroquine, methotrexate, or cyclophosphamide may be helpful. ${ }^{16}{ }^{17}$ A permanent endocardial pacemaker should be used early in patients with unstable or complete heart block; corticosteroids are usually needed in patients who have pacemakers. Reports such as that of Fleming and Bailey ${ }^{18}$ suggest that treatment with corticosteroids results in a reduction in the numbers of premature beats and episodes of tachycardia with easier control of arrhythmias, and an improvement may also be seen in conduction defects. The danger of sudden death may also be diminished. Cardiac transplantation remains a possibility for younger patients with severe intractable heart failure, ${ }^{19}$ but sarcoidosis may recur in the cardiac allograft. ${ }^{20}$

This review indicates the absence of any agreed strategy for the diagnosis, prognosis, and assessment of outcome measures in response to treatment. We believe that patients in whom the diagnosis of cardiac sarcoidosis is thought likely on clinical and electrocardiographic grounds should be further investigated with Holter monitoring and echocardiography reported by a cardiologist with the relevant experience. Expert cardiological advice is needed before embarking on any further cardiological investigations, including myocardial biopsy.

D N Mitchell Honorary consultant physician $\mathrm{R} \mathrm{M}$ du Bois Consultant respiratory physician P J Oldershaw Consultant cardiologist

Directorates of Respiratory Medicine and Cardiology, Royal Brompton Hospital,

London SW3 6NP
1 Scadding JG, Mitchell DN. The heart. In: Sarcoidosis. 2nd ed. London: Chapman and Hall, 1985: 329-48.

2 Mikhail JR, Mitchell DN, Bull KP. Abnormal electrocardiographic findings in sarcoidosis. In: Kiwai, Hosoda Y, eds. Proceedings of 6th international conference on sarcoidosis. Tokyo: University of Tokyo Press, 1974: 365-72.

3 Stein E, Jackler I, Stimmel B, Stein W, Siltzbach LE. Asymptomatic electrocardiographic alterations in sarcoidosis. Am Heart J 1973;86:474-7.

4 Hagemann GJ, Wurm K. The clinical, electrocardiographic and pathological features of cardiac sarcoidosis. In: Jones Williams W, Davies $\mathrm{BH}$, eds. Sarcoidosis and other granulomatous diseases. 8th international conference. Cardiff: Alpha Omega, 1980: 601

5 Matsui Y, Iwai K, Tachihana T, Fruie T, Shigematsu N, Izumi T, et al. Clinico-pathological study on fatal myocardial sarcoidosis. Ann NY Acad Sci 1976;278:445-69.

6 Roberts WC, McAllister HA, Ferrans VJ. Sarcoidosis of the heart. Am J Med 1977;63:86-108.

7 Fleming HA. Death from sarcoid heart disease. United Kingdom series 1971-1986. 300 cases with 138 deaths. In: Grassi C, Rizzato G, Pozzi E, eds. Sarcoidosis and other granulomatous disorders. 11th world congress. Amsterdam: Elsevier, 1988: 19

8 Tellier P, Paycha F, Anthony I, Nitenberg A, Valeyre D, Foult J, et al. Reversibility by dipyridamole of thallium-201 myocardial scan defects in patients with sarcoidosis. Am J Med 1988-85:189-93.

9 Yamamoto N, Gotok K, Yagi Y, Terashima Y, Nagashima K, Sawa T, et al. Thallium-201 myocardial SPECT findings at rest in sarcoidosis. Ann Nucl Med 1993;7:97-103.
10 Taki J, Nakajuma K, Bunko H, Ohgueli M, Tomami N, Hisada K. Cardiac sarcoidosis demonstrated by $\mathrm{Tl}^{201}$ and $\mathrm{Ga}^{-67}$ SPECT imaging. Clin Nucl Med 1990;15:636-7

11 Knapp WH, Bentrup A, Ohlmeir H. Indium-111-labelled antimyosin antibody imaging in a patient with cardiac sarcoidosis. Eur J Nucl Med 1993:20:80-2.

12 Le Guludec D, Menad F, Farraggi I, Weinman P, Battesti J, Valeyre D. Myocardial sarcoidosis: clinical value of technetium-99m-sestamibi tomoscintigraphy. Chest 1994;106:675-82.

13 Ratner SJ, Fenoglio JJ, Ursell PC. Utility of endomyocardial biopsy in the diagnosis of cardiac sarcoidosis. Chest 1986;90:528-53.

14 Oakley C. Cardiac sarcoidosis. Thorax 1989:44:371-2.

15 Warrens AN, Barnes PJ, Cole PJ, Mitchell DN. 'Pulsed' intravenous methyl-prednisolone therapy in refractory sarcoidosis. Thorax 1986;41:714-5

16 Lower EE, Baughman RP. The use of low dose methotrexate on refractory sarcoidosis. Am J Med 1990;229:153-7.

17 Demeter SL. Myocardial sarcoidosis unresponsive to steroids: treatment with cyclophosphamide. Chest 1988;94:202-3.

18 Fleming HA, Bailey SM. Sarcoid heart disease. J R Coll Physicians Lond 1981;15:245-6, 249-53.

19 Scott J, Higenbottam T. Transplantation of the lungs and heart for patients with severe complications from sarcoidosis. Am I Cardiol 1990;66:1329-35.

20 Oni AA. Recurrence of sarcoidosis in a cardiac allograft: control with augmented corticosteroids. J Heart Lung Transplant 1992;11:367-9.

\section{Telling patients they have Alzheimer's disease}

\section{Important for planning their future, and no evidence of ill effects}

$\mathrm{L}$ ast year Conor et al reported that $83 \%$ of family members accompanying patients with Alzheimer's disease to a memory clinic did not want the patients informed of the diagnosis, despite $71 \%$ of relatives stating that they would want to be told themselves. ${ }^{1}$ This finding has stimulated controversy on how doctors should manage this diagnostic information.

In a letter in this week's $B M J$, Barnes reports that $57 \%$ of first degree relatives in his smaller sample wished their relatives to be informed (p 375). ${ }^{2}$ Another letter, from Rice et al (p 376), reports a relation between severity of dementia and the self reported behaviour of consultants in the psychiatry of old age: over $80 \%$ of psychiatrists responding to a questionnaire stated that they rarely informed severely demented patients. In contrast, they reported nearly always sharing diagnostic information with patients with mild dementia. ${ }^{34}$ Another $40 \%$ reported sometimes telling their mildly 
affected patients. Not surprisingly, practice regarding informing "carers" differed in the opposite direction, with the relatives of more severely affected patients being more likely to be given the diagnosis.

Less is known about patient preferences, a fact that may reflect biases of both doctors and investigators. One survey of cognitively intact patients in primary care found a surprisingly high proportion of people stating that they would not want to know their diagnosis. ${ }^{5}$ Extrapolating from the findings of Conor et al, most relatives of patients with Alzheimer's disease, who would have varying degrees of awareness about the genetics of the disorder, would want to know their diagnosis. These reports raise important questions about the nature of doctors' responsibilities, to whom and under what circumstances.

In both Britain ${ }^{6}$ and the United States ${ }^{7}$ patients' right to know is a well established priority. The rationale for withholding information rests on preventing harm. ${ }^{8}$ Arguments that awareness of the diagnosis of Alzheimer's disease does damage by causing stigmatisation and depression ${ }^{9}$ are not based on empirical evidence. Thus, the greater than $20 \%$ prevalence of depression identified in early $\operatorname{cases}^{10}$ may result from a variety of causes, including awareness of memory loss symptoms and the pathophysiology of the disorder. ${ }^{11}$ Despite the association between confrontation of cognitive deficits and transient emotional reactions, there is no evidence of long term sequelae. Furthermore, the ability of patients with Alzheimer's disease to deny their illness through psychological defences ${ }^{12}$ or neuropsychological deficits ${ }^{13}$ mitigates against arguments that awareness of diagnosis leads to lasting psychological damage.

Arguments for informing patients often relate to maintaining the doctor-patient relationship and respecting patient autonomy. ${ }^{9}$ The greater than $90 \%$ accuracy of modern diagnostic criteria negates concern about unduly alarming people who have been misdiagnosed. ${ }^{14}$ The issue may rest more on how patients are told than the precise diagnostic information. Importantly, the results of surveys of the attitudes of family members and psychiatrists cited above occurred outside the context of the doctor-patient relationship. Communication through "patient led" discussions would diminish any adverse emotional effects of sharing painful diagnostic information, a responsibility all doctors share.

Telling a patient the diagnosis of Alzheimer's disease has important substantive benefits. Diagnostic information provides an opportunity for patients (at least, those with capacity to do so) to participate in important decisions about health care and financial planning before further cognitive loss occurs. Patients should know when and why to limit activities such as driving, which has been found to be significantly impaired in patients with mild Alzheimer's disease ${ }^{15}$ Furthermore, the era of "no available treatment" is ending, with access to cholinesterase inhibitors (such as tacrine) that seem to turn back the clock to a point six to 12 months earlier in the disease process. ${ }^{16}$ The availability of new nonacridine agents (such as donepezil), which are both easier to administer and more tolerable, ${ }^{17}$ will offer additional treatment options.

Paradoxically, the fact that cholinesterase inhibitors are palliative rather than curative provides an additional argument for informing patients of their diagnosis. Access to a treatment that cures or stops the progression of Alzheimer's disease entirely will be available initially through randomised research protocols that require informed consent. Currently, most research settings rely on the consent of family members or next of kin. However, the interests of relations do not necessarily correspond with those of the patient. Furthermore, recent court rulings in New York State have rendered consent by family members legally unacceptable,$^{18}$ a decision that may soon apply in other jurisdictions. Thus, patients may be required to arrange consent for potential future treatments before they lose the capacity to understand the nature, risks, and options related to experimental treatments.

Doctors, patients, and family members who share the responsibility for coping with Alzheimer's disease all require access to diagnostic information. Recent findings reported in this journal should be considered as initial research inquiries into an important topic. The need for additional information is crucial; what we do not know, including the attitudes of patients and the actual emotional consequences of having diagnostic information, outweighs the existing evidence. Furthermore, the risks and benefits of having diagnostic information will vary according to the severity of dementia. Additional research must aim to provide doctors with a knowledge base for their interactions with this truly victimised patient population.

Barnett S Meyers Professor of psychiatry

The New York Hospital- Cornell Medical Center,

White Planes, NY 10605,

USA

Conor PM, Kirby M, Coen R, Coakley D, Lawlor BA, O'Neil D. Family members' attitudes toward telling the patient with Alzheimer's disease their diagnosis. BMJ 1996;313:529-30.

2 Barnes RC. Telling the diagnosis to patients with Alzheimer's disease: relatives should act as proxy for patient. BMJ 1997;314:375-6.

3 Rice K, Warner N. Breaking the bad news. What do psychiatrists tell patients with dementia about their illness? Int J Geriatr Psychiatry 1994;9:467-71.

4 Rice K, Warner N, Tye T, Bayer A. Telling the diagnosis to patients with Alzheimer's disease: geriatricians' and psychiatrists' practice differs. BMJ 1997;314:376

5 Erde EL, Nadal EC, Scholl TO. On truth telling and the diagnosis of Alzheimer's disease. J Fam Pract 1988;26:401-6.

6 Department of Health. The patient's charter. London: DoH, 1992

7 President's Commission for the Study of Ethical Problems in Medicine and Biomedical and Behavioral Research. Summing up: final report on studies of the ethical and legal problems in medicine and biomedical research, March 1983. Washington, DC: Government Printing Office, 1983: 65-81.

8 Gillon R. Telling the truth and medical ethics. BMJ 1985;291:1556-7.

9 Drickamer MA, Lachs MS. Should patients with Alzheimer's disease be told their diagnosis? N Engl J Med 1992;326:947-50.

10 Reifler BV, Larson E, Hanley R. Coexistence of cognitive impairment and depression in geriatric outpatients. Am J Psychiatry 1982;139:623-6.

11 Alexopoulos GS, Meyers BS, Young RC, Mattis S, Kakuma T. The course of geriatric depression with reversible dementia: a controlled study. Am J Psychiatry 1992:159;1693-9.

12 Bahro M, Silber E, Sunderland R. How do patients with Alzheimer's disease cope with illness? A clinical experience report. J Am Geriatr Soc 1995;43:41-6.

13 Michen A, Deweer B, Pitlon B, Agid Y, Dubois B. Relation of anosognosia to frontal lobe dysfunction in Alzheimer's disease. J Neurol Neurosurg Psychiatry 1994;57:805-9.

14 Kukull WA, Larson EB, Reifler BV, Lampe TH, Yerby MS, Hughes JP. The validity of 3 clinical diagnostic criteria for Alzheimer's disease. Neurology 1990;40:1364-9.

15 Fitten LJ, Perryman KM, Wilkinson CJ, Little RJ, Burns MM, Pachana N, et al. Alzheimer's disease and vascular dementias and driving: a prospective road and laboratory study. JAMA 1995;273:1360-5

16 Eagger SA, Levy R, Sahakian BJ. Tacrine in Alzheimer's disease. Lancet 1991;337:989-92.

17 Mechcatie E. New Alzheimer's drug delays sentence. Clinical Psychiatric News 1997;25:28.

18 Ross J. Rules over research on mental patients invalid. New York Law Journal 1996 Dec 10:25-30. 